\title{
Are South East Asian Countries Ready for Revalidation Process of Physicians Through Mandatory Continuing Professional Development (CPD) Activities?
}

\author{
Jayarathne Y.G.S.W ${ }^{1}$, Karunathilake, I.M ${ }^{2}$, Marambe, K.N ${ }^{3}$
}

The terms Continuing Medical Education (CME) and CPD have been used interchangeably in most of the countries. CPD is open to many interpretations and the term CME differs from CPD. However, there seems to be a lot of overlapping in the way CME and CPD are defined by the accreditation bodies. The regional guidelines on CME/CPD paper published by the WHO, define CPD as follows. "CPD is beyond clinical update, includes wide-range of competencies like research and scientific writing, multidisciplinary context of patient care, professionalism and ethical practice, communication, leadership, management and behavioural skills, team building, information technology, audit, and appropriate attitudinal change to ensure improved patient service and research outcomes and attainment of the highest degree of satisfaction by stakeholders. The ultimate goals of the programme are to reassure patients and the public that doctors remain competent, confident and compassionate throughout their career and to augment patient care outcome and satisfaction by setting standards for good medical practice" (WHO, 2010, p.1). CME is updating clinical knowledge only. Thus, CME is a component of CPD and CPD involves a wide range of skills required for medical practice.

${ }^{2}$ Professor,

Department of Medical Education

Faculty of Medicine, University of Colombo, Sri Lanka

${ }^{3}$ Director,

Medical Education Unit

Faculty of Medicine, University of Peradeniya, Sri Lanka

\section{Corresponding Author:}

${ }^{1}$ Dr. Y.G.S.W.Jayarathne

Lecturer in Medical Education,

Faculty of Medicine,

Rajarata University of Sri Lanka

Email:wjayarathne@yahoo.com
Currently, many countries have developed as well as amended rules and regulations to practice medicine. Revalidation is the process by which licensed doctors are required to demonstrate that they are up to date and fit to practice and it should be done on a regular basis. It demonstrates to patients and public that their doctors are regularly checked by the governing body (GMC, 2014). It is reported that, CPD is mandatory in most of the countries due to social and political pressure (Davis et al., 1995; Davis, 1998a; George, 2011). Davis et al., 1992 stated that health care outcomes could also be improved by implementing a mandatory CPD system. Hence, it is seen that mandatory CPD activities are essential to improve health care outcomes.

The CPD credit system is one of the main method of documenting CPD activities. However, there is no internationally standardized system for using CPD credits as the evidence of participation in CPD. Awarding CPD credits for different CPD activities seem to vary among countries. Furthermore, it is observed that the number of CPD credits required for relicense and consequences of noncompliance also varies among countries.

\section{Current situation of CPD and revalidation in South East Asian counties}

In Sri Lanka, practice of medicine is only permitted to doctors who have obtained a registration from the Sri Lanka Medical Council (SLMC). The registration is done after successful completion of one year of internship training and renewal of registration takes place four yearly as an administrative process. Currently, CPD is voluntary and the Sri Lanka Medical Association, which is the largest national professional medical association in the country, has commenced a National CPD Certificate programme for all the 
doctors. Doctors are required to collect 50 CPD credits annually to apply for the above certificate. The certificate is valid for three years and renewal should be done in every three years while continuing CPD activities and submitting annual portfolios (National CPD Certificate, 2010). Although the National CPD Certificate is introduced for Sri Lankan doctors, unfortunately, CPD organizing bodies work independently and CPD schemes and CPD provision systems vary across the organizations. On the other hand, standards or criteria have not been set for quality assurance of CPD activities and CPD accreditation bodies are yet to be established in Sri Lanka. In a survey conducted among Grade Medical Officers,(GMOs) working in the Central Province, a vast majority (98\%) perceived CPD as a requirement although around $50 \%$ were willing to undertake mandatory CPD (Jayarathne, 2016). Strangely a majority (83\%) of GMOs were unaware of the National CPD certificate. Further, structured CPD activities with proper planning, notification, feedback mechanism and learning needs analysis are yet to be developed by the CPD providing organizations in Sri Lanka (Jayarathne, 2016). In summary CPD is not a mandatory requirement to practice in Sri Lanka and revalidation is yet to be established.

In 1985, the Continuing Medical Education Cell was started in the Medical Council of India. In addition, the Medical Council of India has made legislations on mandatory $\mathrm{CME}$, that all physicians are required to have 30 hours of $\mathrm{CME}$ every 5 years. However, currently, only 9 out of 28 medical councils have made re-registration of the license to practice mandatory, based on reported CME credit hours. Thus, mandatory CME is not a necessity for relicensing process of all the physicians in India. (Lewis, 2015)

Myanmar Medical Association (MMA) is the main organizing body which is responsible for organizing CPD activities for physicians in Myanmar. MMA conducts regular certificate courses through both face to face and online. In addition, various workshops, seminars, hands-on trainings, clinical meetings, are being conducted by different medical specialty societies (MMA, 2017). However, CPD is not a mandatory requirement for Myanmar doctors.

The Association of Physicians of Bangladesh organize regular CME activities for their doctors in Bangladesh. However, CME is not a mandatory requirement to practice medicine in Bangladesh (APB, 2017).

The Indonesian Medical Association (IMA) and its district agencies are responsible for managing and monitoring $\mathrm{CME}$ programmes in Indonesia and CME is mandatory for re-licensing process. Every physician in practice is required to complete 250 credits every 5 years to achieve a certificate of competence and pass a competency test to have his/her license renewed (Lewis, 2015).

Similarly, in the Maldives doctors are required renew their license to practice through the licensing exam and all the doctors need to renew their license in every 5 years. However, doctors are not required to show evidence of participation in CPD activities as a requirement for licensing exam. Further, if there are licensing lapses, these doctors need to show that they have attended CPD activities as a requirement for licensing examination. Thus, CPD through a licensing exam is a mandatory requirement for Maldivian medical practitioners (MMDC, 2017).

Further, it is also evident that mandatory CPD for physicians is yet to be established in both Thailand and Bhutan.

\section{Conclusion}

It can be concluded that although many developed countries have revised regulations to ensure and enhance professional development of doctors, the current situation in most of South East Asian counties is once qualified and registered, a doctor is licensed to practice for life. Thus, mandatory CPD or revalidation for South East Asian doctors are yet to be a feature and higher authorities of these countries should take lead to implement mandatory CPD to enhance health care outcomes of these countries.

\section{References}

Association of Physicians of Bangladesh, 2017 continuing Medical Education https:www.apbbd.org/what_cme.php

Davis, D. (1998a) Continuing Medical education, global health, global learning, British Medical Journal 316, 7128, pp.385-389. 
Davis, D. A., Thomson, M. A., Oxman, A. D. \& Haynes, R. B. (1992) Evidence for the Effectiveness of CME: A Review of 50 Randomized Controlled Trials. Journal of the American Medical Association 268,9, pp.1111-1117.

Davis, D. A., Thomson, M. A., Oxman, A. D. \& Haynes, R. B. (1995) Changing Physician Performance: A Systematic Review of the Effect of Continuing Medical Education Strategies, Journal of the American Medical Association , 274,9, pp.700-705.

General Medical Council. An introduction to revalidation.(2014)<http://www.gmcuk.org/doctors/9627. asp $>$ [28.02.2014].

General Medical Council. International comparison of ten medical regulatory systems RANDcorporation.(2009)<http://www.rand.org/content/d am/rand/pubs/technical_reports/2009/RAND_TR691.pdf $>$ [23.09.2014].

George, B. M. Continuing professional development the international perspective, GMC.(2011), <www.gmcuk.org/CPD_The_International_ Perspective_Jul_11.pdf_44> [08.05.2014]

Jayarathne, Y.G.S.W. (2016) Exploration of current status of Continuing Professional Development (CPD) among Sri Lankan grade medical officers to develop a CPD provision framework. MD Thesis, Postgraduate Institute of Medicine, University of Colombo, Sri Lanka.

Lewis, A. et al (2015) CME credit systems in three developing countries: China, India and Indonesia. Journal of European CME, 4, pp.27411http://dx.doi.org/10.3402/jecme.v4.27411.

Maldives Medical and Dental council 2017 Licensing Exam http://mmc.gov.mv/
Myanmar Medical Association (2017) Continuing Medical education http://www.mmacentral.org/

National CPD certificate.(2010) Information and Guidance Book. Sri Lanka: Sri Lanka Medical Association.

World Health Organization (WHO).Regional guidelines for continuing medical education (CME) / continuing professional development(CPD)activities.(2010)<https://www.wbgi nvestmentclimate.org/toolkits/health-in-africa-policy toolkit/upload/WHO-CME-Requirements.pdf >( 03/ 05/2013). 
Revalidation in South East Asian Countries 